\title{
Predictors of Improvement in Critical Thinking Skills among Nursing Students in an Online Graduate Nursing Research Course
}

\author{
Patricia A. Riccio \\ College of Nursing and Health Professions, Drexel University, United States
}

Copyright (C) 2015 by authors, all rights reserved. Authors agree that this article remains permanently open access under the terms of the Creative Commons Attribution License 4.0 International License

\begin{abstract}
The purpose of this pilot study was to examine predictors of improvement in critical thinking skills among online graduate nursing students in a graduate nursing research course. Thirty-five students who had taken an online Nursing research course within the prior 12 months and who were currently enrolled in the online graduate Nursing program at Drexel University were sent a link to complete a survey via "survey monkey" ( which is an online data depository) by an honest broker at the University. Time spent in graduate school, course satisfaction, and whether or not a student felt supported were all predictive of improved critical thinking skills in the students. "Connectedness" (within the course, classroom, with the instructor and within the group) remained to be the highest predictor of whether or not students felt their critical thinking skills improved.
\end{abstract}

Keywords Critical Thinking Predictors, Online Nursing Research, Graduate Nursing

\section{Introduction}

Critical thinking has been one educational outcome paramount for learning in all Nursing programs and has been found to be an important skill [1]. Nurses need to make critical judgments about many patient care issues. There also is agreement by credentialing bodies that Universities need to initiate learning experiences to improve critical thinking skills in graduate students [2]. Definitions vary but most agree critical thinking is a cognitive skill which requires logical thinking [1]. At the graduate level, nurses need to translate their thinking from skill-based to concept-based using much more "gray" material to move their practice setting. Concurrently, Universities are increasingly asking graduate students to think in a transformative manner. Thinking in a transformative manner [3] means that instead of acquisitions of skills, which is first order thinking in critical thinking much like that of early Nursing education, focus is on second order thinking or "reflective thinking" and third order thinking which is "thinking about thinking." In other words, students need to engage more in the "new" (transformative thinking) rather than in more of the "same" thinking (adaptive thinking). This mode of thinking requires three abilities -analysis, evaluation and inference- [4] -important intellectual skills in critical thinking required in any Nursing research course This moves Nursing students at Drexel University out of the realm of vocational thinking, into the realm of intellectual thinking at the graduate level, which can move the Nursing profession into a more advanced direction.

Additionally, students in the graduate research courses are increasingly called upon for increased use of research utilization in the practice setting in order to facilitate evidence based practice. What that means is that Nurses must choose which evidence to use or not use. By honing in on transformational critical thinking, Nurses will move the profession into correct decision-making and judgement. In essence, using the transformational critical thinking modality will provide the advanced practice nurse with the skills needed to make sound choices.

In addition to critical thinking, one important concept found from prior work to be a mediating factor in many aspects to the online classroom environment is that of "connectedness." Connectedness as first described by Rovai [5] in the online learning environment has become increasingly important to examine and has been shown to be one of the biggest predictors of student satisfaction and ultimately learning, within the online course [6-9].

Connectedness has been shown to consist of the concepts of trust, respect, and mutuality within the online environment [7]. These concepts of trust, respect, and mutuality impact both the faculty- to- student interaction and also the studentto student- interactions within the classroom setting. Still, very few studies have looked at which qualities influence online instruction- such as those within the concept of 
connectedness- and those which influence outcomes of student learning- such as critical thinking in an online graduate nursing research course $[1,10]$. One meta-analysis study found problem-based learning improved critical thinking skills in nursing students [11]. This study did not include the concept of "connectedness" which seems to be very important in the conduct of the online environment. Given the paucity of studies specifically examining critical thinking skills in an online graduate nursing research course and those factors which might promote or help to improve or mediate this outcome such as "connectedness", this pilot study was developed in order to evaluate predictors of improvement in critical thinking skills among nursing students in an online graduate nursing research course at Drexel University.

\section{Objectives}

The objective of this pilot study was to examine predictors of improvement in critical thinking skills among nursing students in an online graduate nursing research course.

\section{Methods}

A descriptive-correlational design was employed in this study.

\section{a. Sample and Procedure}

A convenience sample of 35 graduate nursing students who were currently enrolled at Drexel University were included in this study. (Out of 100 eligible students, only 35 responded). These students were eligible to enroll in this study if they had taken an online graduate nursing research course within the prior 12 months at Drexel University. The institutional review board approved the study and Human Subjects Consent was obtained in the following manner. Those eligible students were sent a link to complete a survey by a designated individual at the University who was considered an "honest broker." If students agreed to complete the survey and if they sent the survey using the link provided to survey monkey, which is a data depository, their participation was obtained.

Sample characteristics identified respondents' age on the average were 41 years old (ages ranged $=25-60$ years). They were mostly female $(83 \%)$, Caucasian $(80 \%)$, married $(57 \%)$ and working full time $(77 \%)$. In general, the majority of students were working for 10 years or less $(46 \%)$, and had been attending graduate school for 6 months to 1 year (46\%). Most self-reported having a high aptitude for computer skills. The majority of students who had responded reported they had received a grade of $\mathrm{A}$ in the research course they had taken. Finally, most students reported caring for dependents less than 5 hours per day such as caring for children.

\section{b. Data Collection}

There were four categories of questions in the researcher-designed data collection tool: A. Demographic data, B. a qualitative component asking questions such as: "what classroom behaviors were most liked by students?" What behaviors in the classroom could be improved upon by students?" "What behaviors could faculty improve upon in the classroom?" C. Closed ended questions asking items such as: "How would you rate your computer skills using a scale of 1-10?" "Whether or not students worked full time?" "Letter grade they received in the course?" "Perceptions of improvement in critical thinking as an outcome in this course." D. Classroom Community Scale developed by Rovai [5] is a 20-item Likert scale (Total score ranged from $30-75$ with sample means of 48.83,SD 9.51) with two subscales: Connectedness (Mean 21.97, Range 30.75, SD 4.41) and Learning (Mean 26.86, Range 14.35, SD 6.39). Cronbach's alpha coefficient was.86 for the classroom community scale using this sample. Ninety percent agreement using two nurse experts for the qualitative items were used in this instrument for content validity.

\section{c. Data Analysis}

Data were analyzed using SAS 9.2. The outcome variable assessed was critical thinking skills. This variable was dichotomized as either "yes" or "no" regarding critical thinking improvement. Descriptive analysis was performed along with univariate analysis using simple logistic regression to explore the relationship between critical thinking skills and the various predictors, Multivariate analysis was performed to obtain adjusted estimates of the relationship between critical thinking skill improvement and the various predictors using multivariate logistic regression.

\section{Results}

When considering an improvement in critical thinking skills, time spent in graduate school (approximately $* 12.5$ times more likely with a $p$ value of .005) and course satisfaction were all significant predictors of improvement in critical thinking skills (approximately 11.5 times more likely with a $\mathrm{p}$ value of .001). Higher connectedness was associated with an improvement in critical thinking (approximately 11.5 times more likely with a $\mathrm{p}$ value of .001). Specific items most predictive of connectedness were: "confident others will support me, feel connected to others, feel like this course is a family, trust others and feel students in this course care about each other". Males were more likely to report a high degree of connectedness.

Higher amounts of learning on the connectedness scale were associated with an improvement in critical thinking 
(approximately 1.3 times more likely with a $\mathrm{p}$ value of .01). Specific items most predictive were: "felt there was an ample opportunity to learn, felt as if the course did promote a desire to learn, felt educational needs were being met, received timely feedback." Students with positive course satisfaction and positive perceived faculty course satisfaction were more likely to exhibit a high degree of learning. The relationship between an improvement in critical thinking skills and connectedness in the classroom remained the same even after controlling for demographic variables. A similar relationship was detected when examining critical thinking and learning after controlling for the demographic variables.

After adjusting for gender and the amount of time spent in graduate school, the only explanatory variable of perceiving an improvement in critical thinking skills was the connectedness variable ( 1.3 times more likely with a $p$ value of 0.02.).

*These odds-ratios may not be precise estimates due to the small sample size.

\section{Discussion}

Perceived critical thinking improved by course satisfaction and perceived faculty satisfaction with the course. The more satisfied students were with the course and faculty, the more they felt their critical thinking improved. This study also verified that years of study and nurse-associated experience yielded higher levels of critical thinking skills. This was also verified in a prior study [1].

Common themes reported by students as impacting critical thinking centered on "instructor interaction." While this study was a pilot study, it does verify other studies which have suggested the quality and type of interaction has great influence on student learning. Other studies have suggested instructor support, whether it be in the form of feedback or interaction, seems critical to student learning and correspondingly to critical thinking improvement. Perhaps looking at behaviors faculty exude in the classroom might be a future study to examine

The concept of "connectedness" cannot be underestimated. Multiple studies have demonstrated that almost more than any other factor, whether or how much students feel connected is paramount. The more students feel connected to the classroom environment and all aspects of that environment such as with the instructor, the content of the material, the students or with each other, the more likely they will feel as if their critical thinking has improved. Likewise, even student perception of faculty satisfaction with the course seemed to have an impact on student perceptions of their critical thinking improvement.

\section{Conclusions}

Faculty in an online classroom should be concerned about these predictors in order to enhance critical thinking skills among students. They may consider structuring their online course to enhance student perceptions of their feelings of connectedness in the classroom environment. How much support students feel in the online classroom environment seems to impact almost all learning behaviors. Thus faculty should do whatever they can to keep students connected such as create opportunities for faculty to student interactions, student to student interactions and faculty feedback to students. Anecdotally, students have mentioned that the more feedback they received, the more they felt connected to faculty. Even if the feedback was not always positive, they felt more connected. Perhaps this is a result of the isolation students feel working without the structure of a live classroom alone without live students present may be one of the reasons though that is a future research study which might be explored.

Limitations to this study include: the use of a convenience sample which may have produced over or under representing students. A small sample size limited the generalizability of the study. This pilot study only reported data from one graduate nursing program in one geographic area- in Philadelphia, Pennsylvania. No national data were available to determine if the sample was representative of graduate nursing students in the USA. Perhaps a future study could use a sample of students in a more diverse location.

Questions still arise as to exactly what faculty can do to enhance student connectedness? Students want to know that you know they are there by using constant communication with them. Perhaps setting up structured meetings on a routine basis so they know you are available. Provide students with constant feedback which is timely. Some studies have shown that those students who think faculty are satisfied with their own teaching are in fact more connected themselves. Thus, this might be something one could study in the future. Students who felt instructor support were more likely to feel connected and more likely to say their critical thinking skills were improved.

\section{Acknowledgements}

The author wishes to thank the graduate students in the College of Nursing and Health Professions at Drexel University.

\section{REFERENCES}

[1] S. Hunter, V. Pitt, N. Croce, J. Roche. Critical thinking skills of undergraduate nursing students: Description and demographic predictors. Nurse Education Today, Vol.34, 809-814, 2014.

[2] American Association of Colleges of Nursing (AACN). Essentials of Graduate Education in Professional Nursing Practice: Washington, D.C, 2008.

[3] S. Sterling. Sustainable education- Re-visioning learning and 
change. Schumacher Briefing 6, Green Books, Darlington, 2001.

[4] J. Profetto-McGrath, K., Smith, K. Hugo, A. Patel, B. Dussault, Nurse educators' critical thinking dispositions and research utilization. Nurse education in Practice, Vol. 9, 199-208, 2009.

[5] A. Rovai. Development of an instrument to measure classroom community. The Internet and Higher Education. Vol. 5, 197-211, 2002.

[6] J.B. Arbaugh,, R. Benbunan-Fich. The importance of participant interaction in online environments. Decision Support Systems, Vol.43, No.3, 853-865, 2007.

[7] J. Chung-Do, K. Filibeck,, G. Goebert,, G. Arakawa,, D. Fraser,, J. Laboy,, D. Minikawi,. Understanding students' perceptions of a high school course designed to enhance school connectedness. Journal of School Health, Vol. 83, 478-484,
2013.

[8] J. Mahoney, J. Do you feel as if you belong? An online versus face-to-face pilot study. Visions, Vol. 14, No.1, 16-26, 2006.

[9] K. Swan. Building learning communities in online courses: The importance of interaction. Education Communication and Information, Vol. 2, No.1, 23-49, 2002.

[10] A. Dellinger, M. Wells. The effect of type of learning environments on perceived learning among graduate nursing students. Nursing Education Perspectives, Vol. 32, No. 6, 406-411, 2011.

[11] L.N. Kong, B. Qin, Y. Zhou, S. Mou, H. Gao. The effectiveness of problem-based learning on development of nursing students' critical thinking: A systematic review and meta-analysis. International Journal of Nursing Studies, Vol. 51, 458-469, 2014. 